\title{
Solubility of Omeprazole Sulfide in Different Solvents at the Range of $280.35-319.65 \mathrm{~K}$
}

\author{
Yihua Li $\cdot$ Wenge Yang $\cdot$ Tuan Zhang $\cdot$ Chaoyuan Wang • \\ Kai Wang $\cdot$ Yonghong Hu
}

Received: 25 April 2013/Accepted: 7 September 2013/Published online: 12 November 2013

(C) The Author(s) 2013. This article is published with open access at Springerlink.com

\begin{abstract}
Solubility data were measured for omeprazole sulfide in ethanol, 95 mass-\% ethanol, ethyl acetate, isopropanol, methanol, acetone, $n$-butanol and $n$-propanol in the temperature range from 280.35 to $319.65 \mathrm{~K}$ by employing the gravimetric method. The solubilities increase with temperature and they are in good agreement with the calculated solubility of the modified Apelblat equation and the $\lambda h$ equation. The experimental solubility and correlation equation in this work can be used as essential data and model in the purification process of omeprazole sulfide. The thermodynamic properties of the solution process, including the Gibbs energy, enthalpy, and entropy were calculated using the van't Hoff equation.
\end{abstract}

Keywords Omeprazole sulfide - Solubility - Gravimetric method · Purification · Solution thermodynamics

\section{Introduction}

Omeprazole sulfide, an amorphous colorless or white powder, is odorless and stable in air. Omeprazole sulfide $\left(\mathrm{C}_{17} \mathrm{H}_{19} \mathrm{~N}_{3} \mathrm{O}_{2} \mathrm{~S}\right.$, FW 329.42, CAS Registry No. 73590-85-9, structure shown in Fig. 1) is a degradation product of omeprazole. It has been reported to be an antagonist for AHR in HepG2 cells [1] and it acts as an agonist for AHR in human hepatocytes [2]. AHR is aryl hydrocarbon receptor, a mediated transactivation receptortype transcription factor. Omeprazole sulfide is also an important intermediate in pharmaceuticals. It is usually used to synthesize omeprazole and esomeprazole, which are used in the treatment of gastric acid related disorders [3-5] and are effective in the control of gastric acidity of patients with Zollinger-Ellison syndrome, as well as in patients that do

Y. Li $\cdot$ W. Yang $\cdot$ T. Zhang $\cdot$ C. Wang $\cdot$ K. Wang $\cdot$ Y. Hu $(\bowtie)$

College of Biotechnology and Pharmaceutieal Engineering, Nanjing University of Technology, No.

200, North Zhongshan Road, Nanjing 210009, China

e-mail: yonghonghu11@126.com 
Fig. 1 Chemical structure of omeprazole sulfide

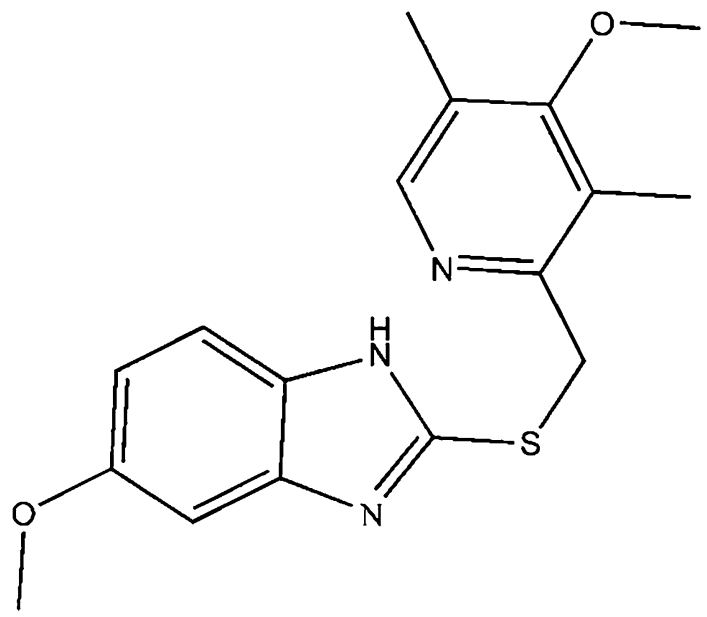

not respond well to histamine $\mathrm{H}_{2}$ receptor antagonists $[3,6]$. In addition, gastrointestinal (GI) diseases account for substantial morbidity, mortality, and cost [7], which leads to the increased demand for the related drugs, such as omeprazole capsules, omeprazole entericcoated tablets, esomeprazole sodium for injection, and esomeprazole magnesium entericcoated tablets. It results in great demand for this key intermediate.

Omeprazole sulfide is synthesized using 2-mercapto-5-methoxybenzene imidazole and 2-chloromethyl-4-methoxy-3,5-lutidine [8] or 4-methoxy-3,5-dimethyl-2-pyridine-methyl bromide [9] as substrate. It should be purified by dissolution, crystallization and separation. Crystallization processes are the critical steps that determine the quality of the product [10] of omeprazole sulfide to provide sufficient purity for the next reaction. So it is very important to know the solubility of omeprazole sulfide as a function of temperature and solvent composition in selected solvents required for the preparation and purification of the products [11]. Moreover, no literature study has reported the correlation between the solubility and temperature or the solvent composition. The most basic information for solving the solvent selection problem is the basic physical properties and solubility data [12]. Therefore we measured and correlated the solubility data of omeprazole sulfide in different solvents (ethanol, 95 mass-\% ethanol, ethyl acetate, isopropanol, methanol, acetone, $n$-butanol and $n$-propanol) over the temperature range $280.35-319.65 \mathrm{~K}$ under atmospheric pressure by the gravimetric method [13, 14]. Thus, systematic and necessary information on the crystallization of omeprazole sulfide was obtained. For predicting the solubility of a solute in different solvents, several methods have been presented $[11,15]$. This study used the modified Apelblat equation and the Buchowski-Ksiazaczak $\lambda h$ equation to correlate and predict the solubility of omeprazole sulfide in different solvents.

\section{Experimental}

\subsection{Materials}

A white crystalline powder of omeprazole sulfide was supplied by Shanghai Lingfeng Chemical Reagent Co., China. The mass fraction was higher than 0.995 , measured by high performance liquid chromatography (HPLC type DIONEX P680 DIONEX Technologies). 
The melting temperature was $392.15 \mathrm{~K}$ determined by differential scanning calorimeter (Netzsch DSC 204). The ethanol, ethyl acetate, isopropanol, methanol, acetone, $n$-butanol and $n$-propanol used for experiment were all analytical purity grade with mass fraction purity higher than 0.995 except for $95 \%$ ethanol. They were supplied by Shanghai Shenbo Chemical Co., Ltd. and used without further purification.

\subsection{Methods}

The solubility of omeprazole sulfide was determined by a gravimetric method. The balance used in these experiments was an analytical balance with an uncertainty of $\pm 0.0001 \mathrm{~g}$ (Sartorius, BS210S). $8 \mathrm{~mL}$ of solvent and a rotor were put into a $10 \mathrm{~mL}$ glass test tube with stopper, and then excess omeprazole sulfide was added into the glass test tube [16]. The test tubes were partly immersed in a constant-temperature bath. The temperature was controlled by a jacketed vessel with water circulated through the outer jacket from a super thermostatic water-circulator bath (type DC-2006 Ningbo XinYi Biotechnology Co., Ltd.). Meanwhile, the inner chamber of the vessel needs a mercury-in-glass thermometer with an uncertainty of $\pm 0.05 \mathrm{~K}$ (calibrated by using a standard thermometer) for measuring the solution equilibrium temperature. Continuous stirring was adopted for fully mixing the suspension with a magnetic stirrer at each temperature [17].

In order to make sure that the solution system established the solid-liquid equilibrium, a stirring time of $12 \mathrm{~h}$ was provided, and then the solution was kept still about $3 \mathrm{~h}$ to ensure a dynamic balance was established between the dissolution and the crystallization processes. Then, about $1 \mathrm{~mL}$ of supernatant was taken from the test tube and transferred to a previously weighed $5 \mathrm{~mL}$ sampling vial using a pre-warmed pipette [17, 18] carefully and quickly. Subsequently, the mass of the sample was determined by weighing the sampling vial again. Then the sampling vial was put into a dryer to dry at room temperature. Afterwards the sampling vial was weighed on a regular basis until it reached a constant weight. Each experiment was repeated at least twice to check the repeatability of the solubility determination, and three samples were taken for each solvent at each temperature [19] and the mean value was considered as the solubility. The saturated mole fraction solubility $(x)$ is obtained from the following equation:

$$
x=\frac{m_{1} / M_{1}}{m_{1} / M_{1}+m_{2} / M_{2}}
$$

where $m_{1}$ represents the mass of solute and $m_{2}$ the mass of solvents. $M_{1}$ is the molecular mass of solute and $M_{2}$ that of the solvent.

\section{Results and Discussion}

\subsection{Solubility Data and Correlation Models}

The saturated mole fraction solubility $(x)$ and the calculated solubility values $\left(x^{\mathrm{c}}\right)$ of omeprazole sulfide in ethanol, $95 \%$ ethanol, ethyl acetate, isopropanol, methanol, acetone, $n$-butanol and $n$-propanol in the temperature range from 280.35 to $319.65 \mathrm{~K}$ are presented in Table 1. 
Table 1 The saturated mole fraction solubility $(x)$ and the calculated solubility values $\left(x^{\mathrm{c}}\right)$ by Eqs. 2 and 3 of omeprazole sulfide, in different solvents at the temperature range from 280.35 to $319.65 \mathrm{~K}$

\begin{tabular}{|c|c|c|c|c|c|}
\hline \multirow[t]{2}{*}{$T / \mathrm{K}$} & \multirow[t]{2}{*}{$x$} & \multicolumn{2}{|c|}{ Equation 2} & \multicolumn{2}{|c|}{ Equation 3} \\
\hline & & $x^{\mathrm{c}}$ & $100 R D$ & $x^{\mathrm{c}}$ & $100 R D$ \\
\hline \multicolumn{6}{|l|}{ Ethanol } \\
\hline 280.35 & 0.0144 & 0.0148 & -2.438 & 0.0142 & 1.507 \\
\hline 284.35 & 0.0189 & 0.0193 & -2.103 & 0.0189 & 0.264 \\
\hline 288.15 & 0.0248 & 0.0247 & 0.415 & 0.0244 & 1.615 \\
\hline 292.25 & 0.0323 & 0.0319 & 1.145 & 0.0318 & 1.490 \\
\hline 296.65 & 0.0412 & 0.0417 & -1.199 & 0.0418 & -1.417 \\
\hline 300.25 & 0.0511 & 0.0514 & -0.734 & 0.0517 & -1.183 \\
\hline 303.15 & 0.0606 & 0.0606 & -0.164 & 0.0610 & -0.670 \\
\hline 307.65 & 0.0775 & 0.0776 & -0.145 & 0.0780 & -0.569 \\
\hline 311.15 & 0.0946 & 0.0934 & 1.269 & 0.0937 & 1.018 \\
\hline 315.15 & 0.1151 & 0.1145 & 0.576 & 0.1145 & 0.571 \\
\hline 319.65 & 0.1415 & 0.1424 & -0.685 & 0.1420 & -0.398 \\
\hline \multicolumn{6}{|c|}{95 mass- $\%$ Ethanol } \\
\hline 280.35 & 0.0101 & 0.0103 & -1.912 & 0.0100 & 0.680 \\
\hline 284.35 & 0.0137 & 0.0138 & -0.882 & 0.0136 & 0.570 \\
\hline 288.15 & 0.0178 & 0.0181 & -1.881 & 0.0180 & -1.194 \\
\hline 292.25 & 0.0240 & 0.0240 & -0.307 & 0.0240 & -0.180 \\
\hline 296.65 & 0.0325 & 0.0323 & 0.861 & 0.0323 & 0.673 \\
\hline 300.25 & 0.0409 & 0.0407 & 0.503 & 0.0408 & 0.224 \\
\hline 303.15 & 0.0489 & 0.0489 & -0.043 & 0.0490 & -0.315 \\
\hline 307.65 & 0.0641 & 0.0643 & -0.213 & 0.0644 & -0.379 \\
\hline 311.15 & 0.0791 & 0.0789 & 0.309 & 0.0789 & 0.259 \\
\hline 315.15 & 0.0989 & 0.0989 & -0.002 & 0.0988 & 0.053 \\
\hline 319.65 & 0.1258 & 0.1260 & -0.101 & 0.1259 & -0.037 \\
\hline \multicolumn{6}{|c|}{ Ethyl acetate } \\
\hline 280.35 & 0.0033 & 0.0032 & 2.293 & 0.0033 & -0.852 \\
\hline 284.35 & 0.0040 & 0.0040 & 2.238 & 0.0040 & 0.389 \\
\hline 288.15 & 0.0049 & 0.0048 & 1.478 & 0.0048 & 0.561 \\
\hline 292.25 & 0.0058 & 0.0059 & -1.126 & 0.0059 & -1.314 \\
\hline 296.65 & 0.0073 & 0.0073 & 0.522 & 0.0072 & 0.839 \\
\hline 300.25 & 0.0085 & 0.0086 & -1.649 & 0.0086 & -1.107 \\
\hline 303.15 & 0.0098 & 0.0099 & -0.273 & 0.0098 & 0.321 \\
\hline 307.65 & 0.0122 & 0.0121 & 0.723 & 0.0120 & 1.233 \\
\hline 311.15 & 0.0142 & 0.0142 & 0.586 & 0.0141 & 0.915 \\
\hline 315.15 & 0.0165 & 0.0169 & -2.217 & 0.0169 & -2.192 \\
\hline 319.65 & 0.0208 & 0.0206 & 1.074 & 0.0207 & 0.669 \\
\hline \multicolumn{6}{|c|}{ Isopropanol } \\
\hline 280.35 & 0.0032 & 0.0033 & -2.520 & 0.0031 & 2.624 \\
\hline 284.35 & 0.0044 & 0.0045 & -2.152 & 0.0043 & 1.309 \\
\hline 288.15 & 0.0058 & 0.0059 & -1.943 & 0.0058 & 0.218 \\
\hline 292.25 & 0.0079 & 0.0080 & -1.311 & 0.0079 & -0.251 \\
\hline
\end{tabular}


Table 1 continued

\begin{tabular}{|c|c|c|c|c|c|}
\hline \multirow[t]{2}{*}{$T / \mathrm{K}$} & \multirow[t]{2}{*}{$x$} & \multicolumn{2}{|c|}{ Equation 2} & \multicolumn{2}{|c|}{ Equation 3} \\
\hline & & $x^{\mathrm{c}}$ & $100 R D$ & $x^{\mathrm{c}}$ & $100 R D$ \\
\hline 296.65 & 0.0108 & 0.0110 & -1.907 & 0.0109 & -1.683 \\
\hline 300.25 & 0.0140 & 0.0141 & -0.475 & 0.0141 & -0.698 \\
\hline 303.15 & 0.0172 & 0.0171 & 0.870 & 0.0172 & 0.439 \\
\hline 307.65 & 0.0234 & 0.0230 & 1.764 & 0.0231 & 1.240 \\
\hline 311.15 & 0.0286 & 0.0287 & -0.405 & 0.0289 & -0.842 \\
\hline 315.15 & 0.0370 & 0.0369 & 0.363 & 0.0369 & 0.204 \\
\hline 319.65 & 0.0482 & 0.0484 & -0.361 & 0.0482 & -0.039 \\
\hline \multicolumn{6}{|l|}{ Methanol } \\
\hline 280.35 & 0.0127 & 0.0135 & -5.842 & 0.0125 & 2.056 \\
\hline 284.35 & 0.0178 & 0.0183 & -2.814 & 0.0175 & 1.973 \\
\hline 288.15 & 0.0239 & 0.0242 & -1.458 & 0.0236 & 1.161 \\
\hline 292.25 & 0.0322 & 0.0325 & -0.975 & 0.0322 & -0.012 \\
\hline 296.65 & 0.0442 & 0.0440 & 0.444 & 0.0441 & 0.293 \\
\hline 300.25 & 0.0559 & 0.0558 & 0.078 & 0.0562 & -0.550 \\
\hline 303.15 & 0.0668 & 0.0673 & -0.629 & 0.0678 & -1.411 \\
\hline 307.65 & 0.0887 & 0.0888 & -0.080 & 0.0894 & -0.768 \\
\hline 311.15 & 0.1103 & 0.1091 & 1.052 & 0.1096 & 0.627 \\
\hline 315.15 & 0.1380 & 0.1367 & 0.974 & 0.1367 & 0.940 \\
\hline 319.65 & 0.1721 & 0.1735 & -0.862 & 0.1728 & -0.446 \\
\hline \multicolumn{6}{|l|}{ Acetone } \\
\hline 280.35 & 0.0050 & 0.0050 & 0.325 & 0.0051 & -0.425 \\
\hline 284.35 & 0.0065 & 0.0065 & 0.257 & 0.0066 & -0.238 \\
\hline 288.15 & 0.0083 & 0.0083 & 0.405 & 0.0083 & 0.108 \\
\hline 292.25 & 0.0108 & 0.0107 & 0.908 & 0.0107 & 0.779 \\
\hline 296.65 & 0.0140 & 0.0140 & 0.339 & 0.0140 & 0.337 \\
\hline 300.25 & 0.0172 & 0.0172 & -0.102 & 0.0172 & -0.035 \\
\hline 303.15 & 0.0203 & 0.0204 & -1.543 & 0.0203 & -1.444 \\
\hline 307.65 & 0.0263 & 0.0262 & 0.335 & 0.0262 & 0.445 \\
\hline 311.15 & 0.0319 & 0.0317 & 0.746 & 0.0317 & 0.832 \\
\hline 315.15 & 0.0390 & 0.0392 & -0.639 & 0.0392 & -0.611 \\
\hline 319.65 & 0.0496 & 0.0495 & 0.181 & 0.0495 & 0.103 \\
\hline \multicolumn{6}{|c|}{$n$-Butanol } \\
\hline 280.35 & 0.0103 & 0.0100 & 2.607 & 0.0102 & 0.882 \\
\hline 284.35 & 0.0134 & 0.0131 & 1.640 & 0.0133 & 0.337 \\
\hline 288.15 & 0.0171 & 0.0169 & 0.958 & 0.0171 & 0.045 \\
\hline 292.25 & 0.0218 & 0.0220 & -0.809 & 0.0221 & -1.334 \\
\hline 296.65 & 0.0292 & 0.0289 & 1.078 & 0.0289 & 0.928 \\
\hline 300.25 & 0.0356 & 0.0359 & -0.641 & 0.0358 & -0.550 \\
\hline 303.15 & 0.0425 & 0.0425 & -0.140 & 0.0424 & 0.094 \\
\hline 307.65 & 0.0549 & 0.0549 & -0.054 & 0.0547 & 0.291 \\
\hline 311.15 & 0.0661 & 0.0666 & -0.655 & 0.0663 & -0.334 \\
\hline 315.15 & 0.0824 & 0.0823 & 0.061 & 0.0822 & 0.204 \\
\hline
\end{tabular}


Table 1 continued

\begin{tabular}{|c|c|c|c|c|c|}
\hline \multirow[t]{2}{*}{$T / \mathrm{K}$} & \multirow[t]{2}{*}{$x$} & \multicolumn{2}{|c|}{ Equation 2} & \multicolumn{2}{|c|}{ Equation 3} \\
\hline & & $x^{\mathrm{c}}$ & $100 R D$ & $x^{\mathrm{c}}$ & $100 R D$ \\
\hline 319.65 & 0.1039 & 0.1037 & 0.225 & 0.1039 & -0.052 \\
\hline \multicolumn{6}{|c|}{$n$-Propanol } \\
\hline 280.35 & 0.0076 & 0.0077 & -1.845 & 0.0076 & -0.541 \\
\hline 284.35 & 0.0101 & 0.0103 & -1.479 & 0.0102 & -0.767 \\
\hline 288.15 & 0.0134 & 0.0134 & -0.416 & 0.0134 & -0.106 \\
\hline 292.25 & 0.0178 & 0.0177 & 0.657 & 0.0177 & 0.690 \\
\hline 296.65 & 0.0234 & 0.0236 & -0.837 & 0.0236 & -0.954 \\
\hline 300.25 & 0.0296 & 0.0297 & -0.158 & 0.0297 & -0.310 \\
\hline 303.15 & 0.0359 & 0.0355 & 1.109 & 0.0356 & 0.972 \\
\hline 307.65 & 0.0470 & 0.0466 & 0.827 & 0.0466 & 0.755 \\
\hline 311.15 & 0.0567 & 0.0571 & -0.600 & 0.0571 & -0.611 \\
\hline 315.15 & 0.0713 & 0.0715 & -0.361 & 0.0715 & -0.323 \\
\hline 319.65 & 0.0914 & 0.0913 & 0.154 & 0.0913 & 0.173 \\
\hline
\end{tabular}

The relationship between temperature and mole fraction solubility in different solvents is described by the modified Apelblat equation, which is a semiempirical equation derived from the Clausius-Clapeyron equation [20, 21], which is as follows:

$$
\ln x=A+\frac{B}{T}+C \ln T
$$

where $T$ represents the absolute temperature, $A, B$ and $C$ are the model parameters, and $x$ is the mole fraction solubility of omeprazole sulfide. The constants $A$ and $B$ represent the variation in the solution activity coefficient and provide an indication of the effect of nonideal solution behavior on the solute solubility, while the constant $C$ reflects the temperature influence on the enthalpy of fusion [22]. The adjustable parameters $A, B$ and $C$ can be obtained by fitting the experimental solubility data.

The Buchowski-Ksiazaczak $\lambda h$ equation is an alternate way to describe solid-liquid equilibrium behavior of omeprazole sulfide, as first proposed by Buchowski et al. [23]. The experimental data for many systems can be well represented by the Buchowski-Ksiazaczak $\lambda h$ equation with only two parameters $\lambda$ and $h$ [24-27]. In this paper, the solubility data were also correlated with the Buchowski-Ksiazaczak $\lambda h$ equation:

$$
\ln \left[1+\frac{\lambda(1-x)}{x}\right]=\lambda h\left[\frac{1}{T}-\frac{1}{T_{m}}\right]
$$

where $T$ represents the system temperature, $T_{m}$ is the melting point temperature of omeprazole sulfide in Kelvin, $x$ is the mole fraction solubility of omeprazole sulfide and $\lambda$ and $h$ are the model parameters determined by the experimental data in the system.

Using the values in Table 1, the parameters of $A, B$ and $C$ were estimated and presented in Table 2, and the parameters of $\lambda$ and $h$ are listed in Table 3, together with the rootmean-square deviations (RMSDs) and the relative average deviations (RADs). 
Table 2 Parameters of Eq. 2 for mole fraction solubility of omeprazole sulfide in various solvents

\begin{tabular}{lrrrrr}
\hline Solvent & \multicolumn{1}{l}{ A } & \multicolumn{1}{l}{$C$} & $10^{2}$ RMSD & $10^{2}$ RAD \\
\hline Ethanol & 169.713 & -12176.733 & -23.160 & 1.082 & 0.973 \\
$95 \%$ Ethanol & 100.445 & -9611.497 & -12.564 & 0.521 & 0.408 \\
Ethyl acetate & -105.237 & 932.180 & 17.069 & 1.069 & 0.945 \\
Isopropanol & 121.765 & -10949.042 & -15.700 & 1.149 & 0.868 \\
Methanol & 290.941 & -18217.582 & -40.870 & 1.125 & 0.930 \\
Acetone & -0.480 & -4587.603 & 2.051 & 0.627 & 0.487 \\
$n$-Butanol & 31.893 & -6080.526 & -2.624 & 0.610 & 0.459 \\
$n$-Propanol & 86.751 & -8848.671 & -10.657 & 0.632 & 0.564 \\
\hline
\end{tabular}

Table 3 Parameters of Eq. 3 for mole fraction solubility of omeprazole sulfide in various solvents

\begin{tabular}{|c|c|c|c|c|}
\hline Solvent & $\lambda$ & $h$ & $10^{2}$ RMSD & $10^{2} \mathrm{RAD}$ \\
\hline Ethanol & 3.582 & 1504.278 & 1.217 & 0.988 \\
\hline $95 \%$ Ethanol & 4.097 & 1447.915 & 0.918 & 0.639 \\
\hline Ethyl acetate & 0.202 & 20201.853 & 1.469 & 1.289 \\
\hline Isopropanol & 1.770 & 3496.429 & 1.496 & 1.279 \\
\hline Methanol & 7.224 & 853.657 & 2.100 & 1.382 \\
\hline Acetone & 1.012 & 5153.445 & 0.659 & 0.525 \\
\hline$n$-Butanol & 2.614 & 2091.202 & 1.093 & 0.806 \\
\hline$n$-Propanol & 2.703 & 2129.557 & 0.922 & 0.767 \\
\hline
\end{tabular}

The RMSD is defined as follows:

$$
\operatorname{RMSD}=\sqrt{\frac{\sum_{i=1}^{N}\left(x^{\mathrm{e}}-x^{\mathrm{c}}\right)^{2}}{N}}
$$

The RAD is defined as follows:

$$
\mathrm{RAD}=\frac{1}{N} \sum_{i=1}^{N}\left|\frac{x^{\mathrm{e}}-x^{\mathrm{c}}}{x^{\mathrm{e}}}\right|
$$

where $N$ is the number of experimental points obtained in each set, which equals the number of temperatures used, $x^{\mathrm{c}}$ represents the calculated solubility values and $x^{\mathrm{e}}$ the experimental solubilities.

The relative deviations (RDs) between the experimental values and the calculated values are also presented in Table 1. The RDs are given as:

$$
\mathrm{RD}=\frac{x^{\mathrm{e}}-x^{\mathrm{c}}}{x^{\mathrm{e}}}
$$

where $x^{\mathrm{c}}$ represents the calculated solubilities and $x^{\mathrm{e}}$ the experimental values.

The $x / T$ curves of omeprazole sulfide, measured in all the solvents studied, are presented in Fig. 2. As we can see from Fig. 2, all the solubility curves are similar, with low solubilities at low temperature, which increase at higher temperatures [28]. The solubility is a function of temperature and increases with increasing temperature. From Fig. 2, it can 


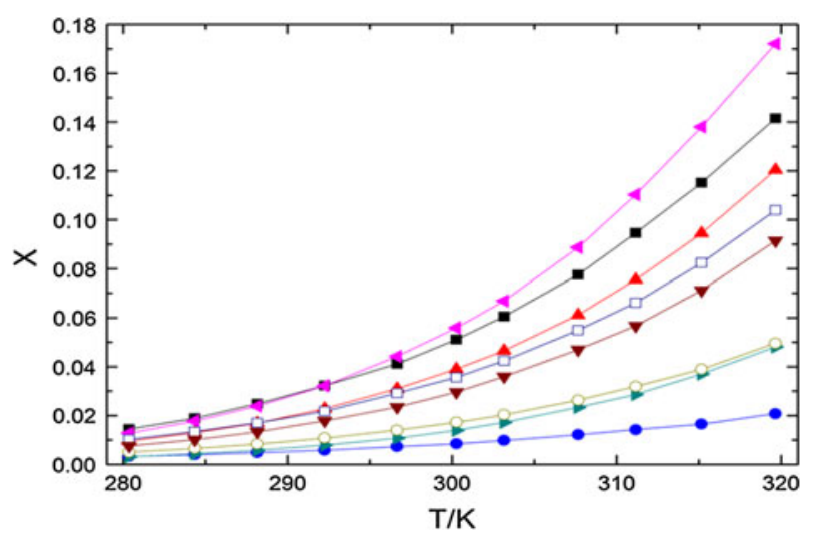

Fig. 2 Solubilities of omeprazole sulfide in different solvents at atmospheric pressure. Left pointing filled triangle methanol, filled square ethanol, filled triangle $95 \%$ ethanol, open square $n$-butanol, inverted triangle $n$-propanol, open circle acetone, right pointing filled triangle isopropanol, filled circle ethyl acetate. Solid lines calculated using Eq. 2

be seen that the solubility of omeprazole sulfide is relatively low in acetone, isopropanol and ethyl acetate at all temperatures. The solubility in ethyl acetate has the smallest percentage change, while the solubility in acetone is substantially the same as in isopropanol. As for the other five solvents, the solubilities are more sensitive to temperature, especially methanol in which the solubility varies much more obviously with temperature, ethanol and $95 \%$ ethanol. So methanol, ethanol and $95 \%$ ethanol can be used to recrystallize omeprazole sulfide. However, in industrial production, taking the safety and cost into account, ethanol or $95 \%$ ethanol presents a potential advantage in the crystallization process of omeprazole sulfide.

As we all know, methanol, ethanol, propanol and butanol are protic solvents that have a hydrogen atom bound to an oxygen (in a hydroxyl group). The molecules of such solvents can readily donate protons and interact with solute molecules by hydrogen bonding. The hydrogen bonds could increase the solubility of the solute. This may be the reason that the solubility is relatively high in methanol, ethanol, $95 \%$ ethanol, $n$-butanol and $n$-propanol. The solubility in methanol and ethanol is higher than that in $n$-propanol and $n$-butanol. This phenomenon can be explained by the fact that when the alcohol chain length increases, the hydrogen bonds with alcohols are weakened [29]. However, the solubility in isopropanol is relatively low, perhaps because the hydroxy of the isopropanol molecules is located between two $\mathrm{CH}_{3}$ groups, which hinder the interaction of the $\mathrm{H}$ and $\mathrm{N}$ atoms. The solubility of omeprazole sulfide is lower in $95 \%$ ethanol than in ethanol. The reason may be that the sulfide compounds are practically insoluble in water.

As can be seen from Tables 1, 2 and 3, the calculated data of omeprazole sulfide in a total of eight solvents show good agreement with the experimental data. For the modified Apelblat equation, as we can see from Tables 1 and 2, the RADs are 0.97, 0.41, 0.95, 0.87, $0.93,0.49,0.46$ and $0.56 \%$, respectively and the absolute values of RDs do not exceed $2.6 \%$, which indicates that all the solubility data can be calculated in the selected solvents when the modified Apelblat equation is used. The same is true for analyzing the solubility data and the parameters that fitted the $\lambda h$ equation. Furthermore, from Tables 2 and 3, all the solubilities are calculated with reasonable RMSD and the average RMSDs are 0.85 and 1.2, for the modified Apelblat and Buchwski-Ksiazaczak $\lambda h$ equations respectively. Therefore the regression result of the modified Apelblat equation is more accurate than the 
Buchowski-Ksiazaczak $\lambda h$ equation. Compared to the Buchowski-Ksiazaczak $\lambda h$ equation, the modified Apelblat equation is proposed for solid-liquid equilibria, and it is widely accepted as being capable of dealing with solvent systems. Therefore, the measured solubility data and the correlation equation in this work can be applied to the design and optimization for the extraction and purification process of omeprazole sulfide [19].

\subsection{Thermodynamic Properties for the Solution}

The temperature dependence of the solubility allows a thermodynamic analysis that permits insight into the molecular mechanisms involved in the solution processes [30]. In this study, the thermodynamic functions in the process of solution of omeprazole sulfide are calculated on the basis of the solubility of omeprazole sulfide in different solvents. The standard molar enthalpy of solution $\left(\Delta H_{\text {soln }}^{\mathrm{o}}\right)$ is accessible from this equation, which is the van't Hoff analysis and defined as [30-32]:

$$
\Delta H_{\mathrm{soln}}^{\mathrm{o}}=-R\left(\frac{\partial \ln x_{1}}{\partial(1 / T)}\right)
$$

where $x_{1}$ is the mole fraction solubility, $R$ represents the universal gas constant $\left(8.314 \mathrm{~J} \cdot \mathrm{K}^{-1} \cdot \mathrm{mol}^{-1}\right)$ and $T$ is the absolute temperature. The standard molar enthalpy change of solution, $\Delta H_{\text {soln }}^{\mathrm{o}}$, is generally obtained from the slope of the solubility curve in a so-called van't Hoff plot where $\ln x$ is plotted against $T^{-1}$. Over a limited temperature interval, the heat capacity change of a solution may be assumed to be constant, hence the derived values of $\Delta H_{\text {soln }}^{\mathrm{o}}$ will also be valid for the mean temperature, $T_{\text {mean }}=300 \mathrm{~K}$ [33]. Equation 7 can also be written as:

$$
\Delta H_{\mathrm{soln}}^{\mathrm{o}}=-R\left(\frac{\partial \ln x}{\partial\left(1 / T-1 / T_{\text {mean }}\right)}\right)
$$

The $\ln x$ versus $\left(1 / T-1 / T_{\text {mean }}\right)$ curves of omeprazole sulfide in the eight solvents are shown in Fig. 3.

The standard molar Gibbs energy of solution $\Delta \mathrm{G}_{\text {soln }}^{0}$ can be calculated according to [34]:

$$
\Delta G_{\text {soln }}^{\mathrm{o}}=-R T_{\text {mean }} \times \text { intercept }
$$

where the intercept used is that obtained in plots of $\ln x$ versus $\left(1 / T-1 / T_{\text {mean }}\right)$. The standard molar entropy of solution is obtained from [30]:

$$
\Delta S_{\mathrm{soln}}^{\mathrm{o}}=\frac{\Delta H_{\mathrm{soln}}^{\mathrm{o}}-\Delta G_{\mathrm{soln}}^{\mathrm{o}}}{T_{\text {mean }}}
$$

The results of the standard Gibbs energy, enthalpy, and entropy of solution are shown in Table 4 , together with $\xi_{H}$ and $\xi_{T S}$. The $\xi_{H}$ and $\xi_{T S}$ represent the comparison of the relative contributions to the standard Gibbs energy by enthalpy and entropy in the solution process, respectively [35].

$$
\begin{aligned}
& \% \xi_{H}=\frac{\left|\Delta H_{\text {soln }}^{\mathrm{o}}\right|}{\left|\Delta H_{\text {soln }}^{\mathrm{o}}\right|+\left|T \Delta S_{\text {soln }}^{\mathrm{o}}\right|} \times 100, \\
& \% \xi_{T S}=\frac{\left|T \Delta S_{\mathrm{soln}}^{\mathrm{o}}\right|}{\left|\Delta H_{\mathrm{soln}}^{\mathrm{o}}\right|+\left|T \Delta S_{\mathrm{soln}}^{\mathrm{o}}\right|} \times 100 .
\end{aligned}
$$

The conclusion can be drawn from Table 4 that the enthalpy and the standard Gibbs energy of solution of omeprazole sulfide are positive in the eight solvents, indicating the 


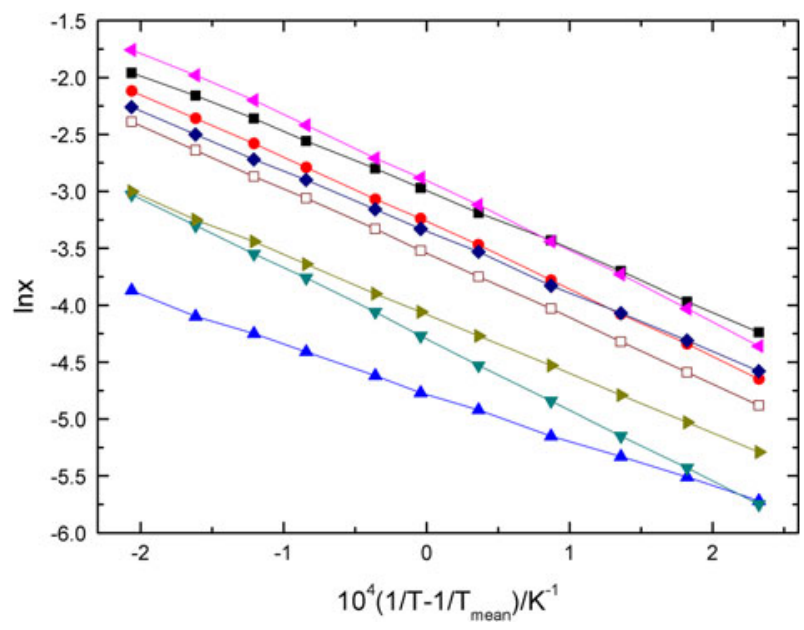

Fig. 3 Mole fraction solubility $(\ln x)$ of omeprazole sulfide in different solvents against $10^{4}\left(1 / T-1 / T_{\text {mean }}\right)$ with a straight line to correlate the data. Left pointing filled triangle methanol, filled square ethanol, filled circle $95 \%$ ethanol, diamond $n$-butanol, open square $n$-propanol, right pointing filled triangle acetone, inverted triangle isopropanol, filled triangle ethyl acetate

Table 4 Thermodynamic functions relative to solution process of omeprazole sulfide in solvents at mean temperature

\begin{tabular}{llcccc}
\hline & $\Delta H_{\text {soln }}^{\mathrm{o}}\left(\mathrm{kJ} \cdot \mathrm{mol}^{-1}\right)$ & $\Delta G_{\text {soln }}^{\mathrm{o}}\left(\mathrm{kJ} \cdot \mathrm{mol}^{-1}\right)$ & $\Delta S_{\text {soln }}^{\mathrm{o}}\left(\mathrm{J} \cdot \mathrm{K}^{-1} \cdot \mathrm{mol}^{-1}\right)$ & $\% \xi_{H}$ & $\% \xi_{T S}$ \\
\hline Ethanol & 43.401 & 7.483 & 119.770 & 54.717 & 45.283 \\
$95 \%$ Ethanol & 48.085 & 8.191 & 133.031 & 54.655 & 45.345 \\
Ethyl acetate & 34.744 & 11.876 & 76.255 & 60.307 & 39.693 \\
Isopropanol & 51.695 & 10.718 & 136.640 & 55.783 & 44.217 \\
Methanol & 49.457 & 7.315 & 140.528 & 53.993 & 46.007 \\
Acetone & 43.286 & 10.170 & 110.427 & 56.656 & 43.344 \\
$n$-Butanol & 43.956 & 8.357 & 118.708 & 55.252 & 44.748 \\
$n$-Propanol & 47.175 & 8.846 & 127.811 & 55.173 & 44.827 \\
\hline
\end{tabular}

solution process of omeprazole sulfide in a total of eight solvents is endothermic. Moreover, the main contributor to the standard molar Gibbs energy of solution is the enthalpy during the dissolution, because the values of $\% \xi_{H}$ are $\geq 54 \%$.

\section{Conclusions}

The solubility of omeprazole sulfide in a total of eight solvents has been measured from 280.35 to $319.65 \mathrm{~K}$ by a dependable experimental method and simple solubility apparatus. For all solvents, solubility is a function of temperature and increases with increasing temperature, but to each increment of temperature they responded with a definite change of solubility. The experimental data were fitted by using the modified Apelblat equation and 
$\lambda h$ equations and the Apelblat equation is more accurate than the $\lambda h$ equation for this system. The calculated solubility of omeprazole sulfide shows good agreement with the experimental values, and experimental solubility data from this work can be used for designing a purification process of omeprazole sulfide. The thermodynamic properties for the solution process including Gibbs energy, enthalpy, and entropy were obtained by the van't Hoff analysis. The thermodynamic parameters values show that the solution process of omeprazole sulfide in a total of eight solvents is endothermic and the larger contributor to the standard molar Gibbs energy of solution is the enthalpy change during the dissolution.

Acknowledgments This experimental work was financially supported by the Natural Science Foundation of the Agricultural Science and Technology Project of JiangSu Province (Grant No. CX (12) 3063, No. CX (12) 3060), the Jiangsu Higher Education Institutions of China (Major projects) (Grant No. 12KJA180002), the College Industrialization Project of Jiangsu Province (Grant No. JHB2011-16), and the Science and Technology support program of JiangSu Province (Agriculture) (Grant No. BE2012373, BE2012374).

Open Access This article is distributed under the terms of the Creative Commons Attribution License which permits any use, distribution, and reproduction in any medium, provided the original author(s) and the source are credited.

\section{References}

1. Yoshinari, K., Ueda, R., Kusano, K., Yoshimura, T., Nagata, K., Yamazoe, Y.: Omeprazole transactivates human CYP1A1 and CYP1A2 expression through the common regulatory region containing multiple xenobiotic-responsive elements. Biochem. Pharm. 76, 139-145 (2008)

2. Chaloin, S.G., Garcia, L.P., Fabre, J.M., Cunha, A.S., Poellinger, L., Maurel, P., Chavanieu, M.D.: Role of CYP3A4 in the regulation of the aryl hydrocarbon receptor by omeprazole sulphide. Cell Signal. 18, 740-750 (2006)

3. González, H.M., Romero, E.M., de Chavez, T.J., Peregrina, A.A., Quezada, V., Hoyo-Vadillo, C.: Phenotype of CYP2C19 and CYP3A4 by determination of omeprazole and its two main metabolites in plasma using liquid chromatography with liquid-liquid extraction. J. Chromatogr. B 780, 459-465 (2002)

4. Walan, A.: Clinical experience with omeprazole: assessment of efficacy and safety. Gastroenterol. Hepatol. 4, 27-33 (1989)

5. Fellenius, E., Berglind, T., Sachs, O., Olbe, L., Elander, B., Sjostrand, S.E., Wollmark, B.: Substituted benzimidazoles inhibit gastric acid secretion by blocking $\left(\mathrm{H}^{+}+\mathrm{K}^{+}\right)$ATPase. Nature 290, 159-161 (1981)

6. Landry, H.D., Wilde, M.I.: Omeprazole: a review of its use in helicobacter pylori infection, gastrooesophageal reflux disease and peptic ulcers induced by nonsteroidal anti-inflammatory drugs. Drugs 56, 447-486 (1998)

7. Peery, A.F., Dellon, E.S., Lund, J., Crockett, S.D., McGowan, C.E., Bulsiewicz, W.J., Gangarosa, L.M., Thiny, M.T., Stizenberg, K., Morgan, D.R., Ringel, Y., Kim, H.P., DiBonaventura, M.D., Carroll, C.F., Allen, J.K., Cook, S.F., Sandler, R.S., Kappelman, M.D., Shaheen, N.J.: Burden of gastrointestinal disease in the United States: 2012 Update. Gastroenterology 143, 1179-1187 (2012)

8. Brandstrom, A. E., Lamm, B. R.: Processes for the preparation of omeprazole and intermediates thereof. US Patent: 4620008 (1986)

9. Joseph, K.M., Sanchez, I.L.: Synthesis of benzyl bromides with hexabromoacetone: an alternative path to drug intermediates. Tetrahedron Lett. 52, 13-16 (2011)

10. Yang, W.G., Hu, Y.H., Chen, Z.G., Jiang, X.M., Wang, J.K., Wang, R.R.: Solubility of itaconic acid in different organic solvents: experimental measurement and thermodynamic modeling. Fluid Phase Equilib. 314, 180-184 (2012)

11. Jiang, R.Y., Wang, L.S.: Solubilities of hexaphenoxycyclotriphosphazene and tri(2-cyanoethyl)phosphine in selected solvents: measurement and correlation. J. Solution Chem. 41, 2107-2122 (2012)

12. Zhao, Y., Wang, Y.L.: Measurement and correlation of solubility of tetracycline hydro-chloride in six organic solvents. J. Chem. Thermodyn. 57, 9-13 (2013) 
13. Yang, H.Y., Rasmuson, A.C.: Solubility of butyl paraben in methanol, ethanol, propanol, ethyl acetate, acetone, and acetonitrile. J. Chem. Eng. Data 55, 5091-5093 (2010)

14. Zheng, Y.L., Liu, X.S., Luan, L.J., Wang, L.H., Wu, Y.J.: Solubility of physalin D in ethanol, methanol, propanone, trichloromethane, ethyl ethanoate, and water at temperatures from 283.2 to $313.2 \mathrm{~K}$. J. Chem. Eng. Data 55, 3690-3692 (2010)

15. Wang, Z.Z., Dang, L.P.: Measurement of solubility of erythromycin acetone solvate in aqueous acetone solution between 298 and 323 K. Fluid Phase Equilib. 276, 94-98 (2009)

16. Brandani, S., Brandani, V., Flammi, D.: Solubility of trioxane in water. J. Chem. Eng. Data 39, 201-202 (1994)

17. Hu, Y.H., Jiang, X.M., Yang, W.G., Chen, Z.G., Meng, X.Q., Shen, F.: Solubility of erythritol in different aqueous solvent mixtures. J. Mol. Liq. 169, 74-79 (2012)

18. Jiang, Q., Gao, G.H., Yu, Y.X., Qin, Y.: Solubility of sodium dimethyl isophthalate-5-sulfonate in water and in water + methanol containing sodium sulfate. J. Chem. Eng. Data 45, 292-294 (2000)

19. Fan, J.P., Xie, Y.L., Tian, Z.Y., Xu, R., Qin, Y., Li, L., Zhu, J.H.: Solubilities of evodiamine in twelve organic solvents from $T=283.2$ to $323.2 \mathrm{~K}$. J. Chem. Thermodyn. 58, 288-291 (2013)

20. Jia, Y.X., Qian, C., Chen, X.Z., He, C.H.: Solubilities of 3-methoxy- $N$-phenylaniline and 3-(methylthio)- $N$-phenylaniline in five organic solvents (285 to $333.75 \mathrm{~K}$ ). J. Chem. Eng. Data 57, 1581-1585 (2012)

21. Zhang, J., Hu, J.W., Wang, J.L., Chen, L.Z.: Solubility of 1,3,3-trinitroazetidine in ethanol + water systems from 293.15 to 323.15 K. J. Solution Chem. 40, 703-708 (2011)

22. Heryanto, R., Hasan, M., Abdullah, E.C., Kumoro, A.C.: Solubility of stearic acid in various organic solvents and its prediction using non-ideal solution models. Sci. Asia 33, 469-472 (2007)

23. Buchowski, H., Ksiazczak, A., Pietrzyk, K.: Solvent activity along a saturation line and solubility of hydrogen-bonding solids. J. Phys. Chem. 84, 975-979 (1980)

24. Ksiazczak, A., Kosinski, J.J.: Vapour pressure of binary, three-phase (S-L-V) systems and solubility. Fluid Phase Equilib. 44, 211-219 (1988)

25. Ksiazczak, A., Moorthi, K., Nagata, I.: Solid-solid transition and solubility of even $n$-alkanes. Fluid Phase Equilib. 95, 15-29 (1994)

26. Bao, Y., Wang, J.K., Wang, Y.L., Qi, Z.: The Measurement and correlation of solubility of spectinomycin dihydrochloride in pure water and acetone-water mixture. J. Chem. Eng. Chin. Univ. 17, 457-461 (2003)

27. Ma, P.S., Chen, M.M.: Solid-liquid equilibrium of terephthalic acid in several solvents. Chin. J. Chem. Eng. 11, 334-337 (2003)

28. Chen, F.X., Zhao, M.R., Ren, B.Z., Zhou, C.R., Peng, F.F.: Solubility of diosgenin in different solvents. J. Chem. Thermodyn. 47, 341-346 (2012)

29. Lim, J., Jang, S., Cho, H.K., Shin, M.S., Kim, H.: Solubility of salicylic acid in pure alcohols at different temperatures. J. Chem. Thermodyn. 57, 295-300 (2013)

30. Wang, S., Qin, L.Y., Zhou, Z.M., Wang, J.D.: Solubility and solution thermodynamics of betaine in different pure solvents and binary mixtures. J. Chem. Eng. Data 57, 2128-2135 (2012)

31. Wei, D.W., Li, H., Li, Y.N., Zhu, J.: Effect of temperature on the solubility of 3-aminopyridine in binary ethanol + toluene solvent mixtures. Fluid Phase Equilib. 316, 132-134 (2012)

32. Maher, A., Croker, D., Rasmuson, A.C., Hodnett, B.K.: Solubility of form III piracetam in a range of solvents. J. Chem. Eng. Data 55, 5314-5318 (2010)

33. Ruidiaz, M.A., Delgado, D.R., Martínez, F., Marcus, Y.: Solubility and preferential solvation of indomethacin in 1,4-dioxane + water solvent mixtures. Fluid Phase Equilib. 299, 259-265 (2010)

34. Zhou, X.Q., Fan, J.S., Li, N., Du, Z.X., Ying, H.J., Wu, J.L., Xiong, J., Bai, J.X.: Solubility of Lphenylalanine in water and different binary mixtures from 288.15 to $318.15 \mathrm{~K}$. Fluid Phase Equilib. 316, 26-33 (2012)

35. Azar, V.P., Ahmadian, S., Martínez, F., Acree Jr, W.E., Jouyban, A.: Thermodynamic studies of fluphenazine decanoate solubility in PEG 200 + water mixtures. Fluid Phase Equilib. 330, 36-43 (2012) 